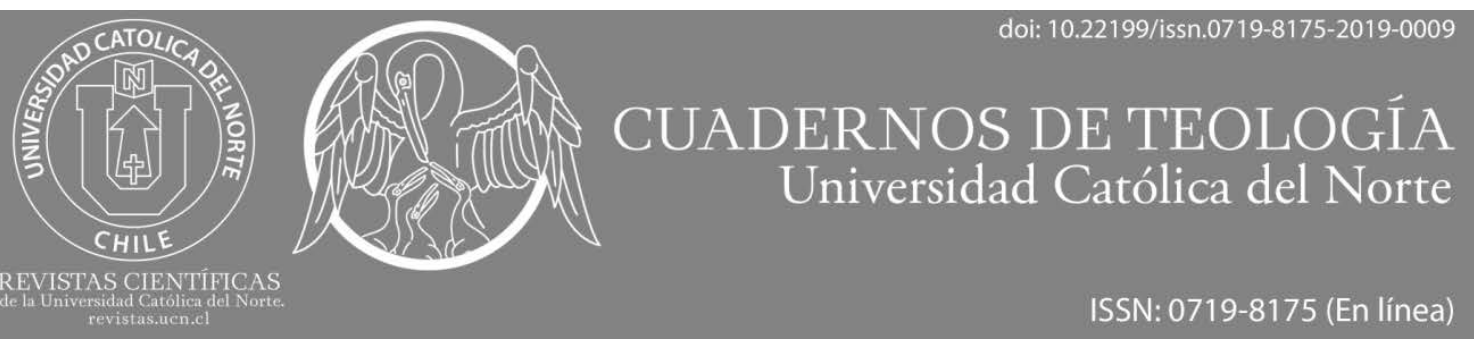

\title{
La paz de la fe de Nicolás de Cusa: ¿un antecedente del diálogo
} interreligioso?

The peace of faith of Nicolás de Cusa: a history of interreligious dialogue?

Fabián Rodríguez Medina* (D) https://orcid.org/0000-0002-4585-6211

*Universidad de las Américas, Santiago, Chile. Magíster en Cs. Religiosas y Filosóficas mención Teología Fundamental, U. Católica del Maule. filrodriguez88@gmail.com

(cc) BY

\section{Resumen:}

Nicolás de Cusa (1401-1464) fue un filósofo y teólogo de fines de la Edad Media que presenció la caída del Imperio Bizantino, tras la irrupción del Islam en Occidente. Desde entonces procuró aportar filosóficamente para el entendimiento de la diversidad de ritos religiosos y su convergencia en una paz entre los mismos, a partir de la tolerancia. Se abordará la propuesta de dicho autor en su obra La paz de la fe como un posible precedente para el diálogo interreligioso.

Palabras Clave: Tolerancia; Pluralidad religiosa; Concordia; Consenso.

\section{Abstract:}

Nicolás de Cusa (1401-1464) was a philosopher and theologian of the end of the Middle Ages who witnessed the fall of the Byzantine Empire, after the irruption of Islam in the West. Since then he has tried to contribute philosophically to the understanding of the diversity of religious rites and their convergence in a peace between them, based on tolerance. This author's proposal is addressed in his work Peace of Faith as a possible precedent for interfaith dialogue.

Keywords: Tolerance; Religious plurality; Concord; Consensus. 


\section{Atisbos de tolerancia en "La paz de la fe"}

¿Qué motivó a que el Cusano escribiera La paz de la fe? Nicolás de Cusa fue motivado en primer lugar, por una profunda inquietud personal que dejó en él la toma de Constantinopla (Nicolás de Cusa, 1996, p. 49), la cual generó la caída del Imperio Bizantino. Acontecimiento provocado por los turcos otomanos, quienes seguían las enseñanzas del profeta Muhammed (o Mahoma) escritas en el texto sagrado del Corán.

Dicho acontecimiento marcó radicalmente su vida, por lo que consideró necesario como filósofo y teólogo, buscar vías de diálogo entre las distintas religiones que contribuyeran a la paz entre ellas; principalmente entre la nueva forma religiosa que irrumpía en el viejo continente - el Islam - con el judaísmo y el cristianismo, pero también con otras espiritualidades.

Entonces presenta en el inicio de la obra una visión intelectual que tuvo un hombre (que no es otro que él mismo), luego de presenciar la caída de Constantinopla, donde conversa el Rey o Señor que representa a Dios, con el Verbo, y éste, con distintos representantes de la diversidad de ritos o religiones.

De entrada, debe aclararse que lo que hace Nicolás es ir mostrando un diá- logo entre distintos personajes con una concatenada argumentación especulativa, sin apoyarse en las Escrituras ni mucho menos en la Revelación, pues todo el ejercicio dialógico que pone en boca de los participantes es racional, es decir, filosófico, aunque tiene implicancias teológicas'.

El desenlace de la obra es llevado a cabo por la interacción entre el Verbo de Dios, es decir, Cristo encarnado de acuerdo a la teología cristiana, y alrededor de 17 personalidades: el Griego, el Italiano, el Árabe, el Indio, el Caldeo, el Judío, el Escita, el Francés, el Persa, el Sirio, el Español, el Turco, el Alemán, el Tártaro, el Armeno, El Bohemio, y el Inglés. Además, intervienen dos apóstoles: Pedro y Pablo.

Hasta aquí solamente se ha indicado aspectos superficiales de la obra cusana. Sin embargo, es preciso abordar ahora los aspectos centrales del texto y que guardan relación con la temática que se pretende demostrar. Esto es, si La paz de la fe es o no un precedente para lo que hoy parece ser un nuevo paradigma teológico contemporáneo: el diálogo interreligioso.

\footnotetext{
${ }^{1}$ Las implicancias teológicas del diálogo que presenta el Cusano son cuestiones teológicas como la Trinidad, la encarnación, el Reino de Dios, la justificación por la fe, pero no desde una perspectiva dogmática, sino filosófica. A pesar de ello, se nota el conocimiento bíblico del autor, puesto que, si bien no cita textos bíblicos, estos están implícitos en la obra.
} 
Al igual que en la actualidad, en época de Nicolás de Cusa existía una pluralidad religiosa. Dicha diversidad de ritos de las religiones (Nicolás de Cusa, 1996, p. 49) como el mismo le denomina, se dejaba ver y se hacía sentir en Europa, por lo que urgía alguna forma de poner en contacto a sus principales representantes. La finalidad era lograr la paz o concordia entre las distintas religiones. Para ello se requería que interactuaran a partir de la diversidad de sus propios elementos teológicos y filosóficos, pero buscando algún consenso en base a componentes comunes.

¿Qué tienen en común las religiones para el Cusano? Expresa Nicolás que cada religión apetece el bien, y que este bien mayor no es otro que el mismo Dios: Tú que das la vida y el ser, eres el que pareces ser buscado de modo diferente por las diversas religiones y nombrado con diferentes nombres, pues permaneces para todos desconocido e inefable en tu verdadero ser (Nicolás de Cusa, 1996, p. 51).

Al parecer, las distintas religiones intentan alcanzar el bien último, es decir, la divinidad, el Absoluto, Dios, mediante nombres que difieren entre ellos, pues responden a su manera de concebir a la Deidad. No obstante, los nombres que le son asignados no agotan su esencia, y pese a que nominalmente pueda el ser humano aproximarse a la divinidad, no llegan a una cognoscibilidad plena de ella, pues su ser resulta totalmente desconocido.

El Cusano, siguiendo la tradición medieval-escolástica del Deus absconditus, reflejo de un apofatismo neoplatónico ${ }^{2}$, declara a través del diálogo entre el Verbo y otros personales, que la divinidad es un ser simplícimo. Es más, señala que Dios es la sabiduría simplícima (Nicolás de Cusa, 1996, p. 54), es el principio simplícimo (Nicolás de Cusa, 1996, pp. 60-61), es la unidad simplícima (Nicolás de Cusa, 1996, p. 62), es la fecundidad simplícima (Nicolás de Cusa, 1996, p. 63). Incluso sostiene Cusa que "del Dios simplicísimo no se puede decir nada verdadero que no sea El mismo" (Nicolás de Cusa, 1996, p. 64). Y pasando a aspectos más teológicos y dogmáticos, dice que Dios es la simplícima trinidad (Nicolás de Cusa, 1996, pp. 64-65), y que, en cuanto eternidad, es trina y simplícima (Nicolás de Cusa, 1996, pp. 65-66).

Por otra parte, es importante señalar que para el Cusano, otro aspecto que tendrían en común las religiones sería su origen. Éste radicaría en poder alcanzar la felicidad, puesto que toda religión de una u otra forma, como diría la filósofa

\footnotetext{
${ }^{2}$ Este apofatismo en el cual se enmarca el pensamiento Cusano, propone un acceso a la divinidad más allá de todo discurso afirmativo, puesto que Dios es más de lo que se suele afirmar.
} 
española Cortina Orts (1999, p. 167), ofrece una invitación y no una imposición a adherirse a su sistema de creencias, que en el fondo no es otra cosa que una ética de máximos. La felicidad ofrecida por las religiones resulta ser una cuestión soteriológica, esto es, una forma de vivenciar la salvación, en esta vida o en la venidera. Así lo expresa Cusa:

" $Y$, puesto que todos esperan poder alcanzar algún día la felicidad, por la que existe toda religión, y en este punto no cabe ser decepcionado ya que esta esperanza es común a todos por un deseo innato, al que sigue la religión, que, por consiguiente, existe igualmente innata en todos (...)". (Nicolás de Cusa, 1996, p. 75).

La tan anhelada felicidad que persigue todo hombre y toda mujer, y que las religiones pretenden brindar, se corresponde o relaciona con la idea teológica de la vida eterna y la noción teológicametafísica de la inmortalidad. Sólo así el ser humano puede enlazar su naturaleza mortal y finita directamente con la naturaleza inmortal e infinita de la divinidad.

Nicolás manifiesta que:

"Los hombres no desean la felicidad, que es la vida eterna misma, en otra cosa que no sea en su propia naturaleza el hombre no quiere ser sino hombre, no ángel u otra naturaleza; quiere ser un hombre feliz, que obtenga la felicidad última. Esta felicidad no es sino el goce o unión de la vida humana con su fuente, de la que emana la misma vida, que es la vida divina inmortal" (Nicolás de Cusa, 1996, p. 74).

El Cusano pone en boca del Sirio que la paz puede encontrarse en cualquier secta, pues no solamente en las religiones monoteístas, sino también en otras se puede encontrar la creencia en una vida eterna, o en la inmortalidad, como causas segundas de la resurrección" (Nicolás de Cusa, 1996, p. 73).

Aunque existen aspectos que son compartidos por las diversas religiones, hay también elementos detractores que impiden la concordia entre ellas. Es el caso del monopolio de la verdad que cada una cree poseer, en cuanto a la salvación. Ante esto, el Cusano insiste en la unidad de la fe religiosa de la diversidad de ritos.

De ahí que proponga el consenso como posible vía de acceso a la unidad de la fe, dado que el Señor se ha compadecido de su pueblo y ha decidido, mediante un consenso común de todos los hombres, que la diversidad de religiones sea armoniosamente reducida a una sola, que 
será en adelante inviolable (Nicolás de Cusa, 1996, pp. 53-54).

Aquí el Cusano plantea que lo ideal es que haya una reducción a una sola fe. Sin embargo, esto difiere de lo que expone más adelante, y hasta podría entrar en contradicción. Señala que solamente Dios "puede hacer que tal diversidad de religiones sea conducida a una paz armoniosa" (Nicolás de Cusa, 1996, p. 54). Digo que podría haber una contradicción en lo que respecta a aminorar las religiones a una sola, $y$, por otra parte, afirmar que todas deben ser conducidas a la concordia. Pero lo que parece sostener Nicolás de Cusa no es que algunas religiones desaparezcan, quedando una sola: la cristiana por ser la mejor o la verdadera. Sino que ellas tienen la obligación de aprender a convivir en paz, a partir de aquellos elementos que tienen en común y que fueron mencionados anteriormente. Además, propone para conseguir la paz religiosa el valor de la tolerancia, aunque solamente lo mencione una única vez a lo largo de su obra. Momento crucial, ya que no lo sostiene cualquier personaje, sino uno de los apóstoles; Pablo, quien dice "si, por razones religiosas, han tolerado (...)". Tolerancia que "no debe ser entendida en este caso como una actitud pasiva en la cual se soporta la diferencia aun cuando no se la comparta sino más bien como la cons- trucción activa de la concordia" (D'Amico, 2012).

Para el Cusano, la tolerancia es por ningún motivo una postura indiferente tal y como algunos entienden dicho valor en nuestra sociedad, porque para él tiene que ver con una praxis de vida que involucre una valoración del otro en tanto es distinto a mí, por tener otras creencias religiosas en este caso.

Un valor que este filósofo trataba de situar en la contingencia todavía medieval, aunque con aires renacentistas. Valor que más tarde sería promovido en la modernidad. Tolerancia cuyo objetivo ha perseguido en materia interreligiosa la paz perpetua, puesto que, en la mayoría de los casos, las guerras son motivadas por la religión o alguna de sus causas se debe ella.

El fundamento de la paz interreligiosa es la paz o concordia entre los diversos credos religiosos. Así lo previó el Cusano, pero al parecer su obra no fue tomada en cuenta.

No es menor el hecho que Nicolás de Cusa haya considerado a las religiones politeístas, las que también tendrían que interactuar con las religiones monoteístas mediante la tolerancia para convivir en paz. Y es que la fe politeísta implicaría una fe en lo divino, lo cual resulta esencial, 
porque es también un aspecto que llega a formar parte de los elementos comunes a las religiones. Quien da cuenta de esto es el Verbo: "Todos los que alguna vez dieron culto a varios dioses han presupuesto la existencia de la divinidad, a la que adoran como una misma en todos los dioses que participan de ella (Nicolás de Cusa, 1996, pp. 57).

Como ya se dijo anteriormente, Cusa se percató que las guerras e invasiones de unos pueblos sobre otros tenían su origen en la religión, y lo expresa claramente cuando sostiene que "por causa de la religión muchos se levantan en armas" (Nicolás de Cusa, 1996, p. 50). Ante eso el Cusano afirma que puede llegar a darse la paz o concordia entre pueblos con distintas religiones, pero que esta paz dependería de la intervención de Dios (Nicolás de Cusa, 1996, pp. 51-52) por una parte, pero por otra, de la participación del ser humano (Nicolás de Cusa, 1996, p. 51) en cuanto debe cooperar de algún modo para conseguir la paz. Dios interviene porque se compadece de la humanidad, queriendo que los hombres puedan alcanzar el consenso de poder reducir la fe (Nicolás de Cusa, 1996, pp. 53-54).

A raíz de lo anterior, y de otros planteamientos cusanos, se puede apreciar en su obra, el teocentrismo propio del mundo medieval, aunque con matices, dado que entre líneas se notan ya atisbos de una antropología moderna. Nicolás se refiere en algunas oportunidades a la autonomía humana, pero anclada a cuestiones religiosas. Por ejemplo, dice que "son pocos los que gozan del ocio necesario para que, en uso de libertad, puedan profundizar en el conocimiento propio" (Nicolás de Cusa, 1996, p. 50). Libertad que ha sido otorgada al ser humano por el mismo Dios (Nicolás de Cusa, 1996, pp. 52-53).

De la antropología filosófica cusana, se sigue una antropología teológica en la medida en que la autonomía del ser humano se relaciona con la fe religiosa, porque la fe es una respuesta personal de cada individuo ante la divinidad llevada a cabo en su propia libertad, porque hay quienes no responden. Una fe que como bien defiende el Cusano por medio del "apóstol de las gentes", es condición necesaria para obtener la salvación. Esto quiere decir que lo único que salva es la fe (Nicolás de Cusa, 1996, p. 81) y no los ritos, por lo que todas las religiones coincidirían también en la fe en Dios o lo divino, aunque den cuenta de ella de diversas maneras.

Otra característica de la antropología teológica que se desprende de $L a$ paz de la fe es, su alusión a la felicidad y su relación con la vida eterna, siendo a su vez una bendición divina (Nicolás de Cusa, 
1996, p. 82) que está disponible para la vida humana. Felicidad a la que todo ser humano aspira, puesto que "todos nacemos con el deseo innato de ser felices" (Nicolás de Cusa, 1996, pp. 74-75).

Y el último elemento de la antropología teológica cusana que se puede extraer es lo que guarda relación con la ética. Después que Pablo y el Tártaro dialogan sobre la fe como lo único que puede justificar al ser humano para una vida eterna, pero que debe ir acompañada de obras, es decir, de una praxis o actuar del hombre. Un comportamiento moral basado en la regla de oro; en el amor y el respeto por el prójimo: "pues Dios habla en nosotros, para que amemos a aquel de quien recibimos el ser y para que no hagamos al prójimo lo que no queremos que nos hagan a nosotros mismos" (Nicolás de Cusa, 1996, p. 84).

Por otro lado, es un hecho que existen distintas religiones. La razón de ello se debe, según el propio Cusano, a Dios. Él es la causa del pluralismo religioso, puesto que habría enviado por diferentes lugares a profetas y maestros espirituales (Nicolás de Cusa, 1996, pp. 50-51). Como cada pueblo a través de su respectiva religión cree tener la verdad, defendiendo sus prácticas y sus verdades de fe, fue necesario algún mecanismo para llegar primeramente a consensos, y luego a la concordia entre las religiones. Consenso dialógico como el que pretendió ofrecer Nicolás de Cusa, por lo que podría aseverarse que se trataría de un antecedente para el diálogo interreligioso. Pero ¿qué es el diálogo interreligioso?

\section{Diálogo interreligioso y La paz de la fe \\ El denominado diálogo interreli-} gioso es una práctica del quehacer teológico contemporáneo, por parte del cristianismo católico y protestante, de generar instancias dialógicas de encuentro con religiones no cristianas (Sampedro Nieto, 2013, p.158), como el judaísmo, el islam, el hinduísmo y el budismo.

Es también un intento antropológico por reconocer otras subjetividades y sus propias particularidades, especialmente en lo religioso, a partir de uno de los saberes pertenecientes a las denominadas ciencias humanas $y / 0$ hermenéuticas: la teología. Un intento antropológico por el hecho de que puede contribuir al rescate $y$ al reconocimiento del otro en su singularidad y en el aspecto esencial que aquí nos interesa: lo religioso.

Por medio del diálogo interreligioso en la praxis misma del día a día, en las relaciones interpersonales y por lo mismo, intersubjetivas que tenemos con los demás. Debemos reconocerlos como un Tú 
particular que es también un Yo, como diría Buber (1949, p. 12), para quien la intersubjetividad se daría en base a relaciones Yo-Tú y Yo-Ello. Además, aquí es donde el Tú que es el otro, se relaciona también con lo divino, pero de una manera diferente al Yo. El reconocimiento debería tener lugar en la singularidad de cada persona. En cuanto tiene una convicción religiosa distinta a la del otro y como tal, debe ser aceptada y reconocida en una horizontalidad de respeto, tolerancia, amistad, aceptando que el otro puede tener razón y tener, lo que es más importante aún, su propia verdad religiosa, sin que excluya por eso a otras que puedan existir como posibilidades.

La religión, y por ende lo religioso, ha sido transformada e instrumentalizada al servicio de ciertas ideologías políticas y económicas expansionistas, respaldadas por un creciente armamento bélico que en su mayor parte es nuclear, permitiendo que hoy día podamos darnos cuenta de bloques, tanto en occidente como en oriente. Sucede que las religiones son usadas para conseguir adeptos a intereses que favorezcan al mercado mundial. $Y$ en este juego deben competir. Ante esto se hace urgente la necesidad de que las distintas religiones que hay en nuestro mundo entren y lleguen a formar parte de este nuevo paradigma del diálogo interreligioso (y también resulta relevante y hasta atingente la propuesta cusana), que apunta a trascender el intento teológico de la inclusividad $^{3}$ por sobre la exclusividad de la revelación de Dios. Es crucial esta instancia para fomentar, mantener y seguir contribuyendo en la paz mundial, ya que como afirma Hans Küng (1998, p. 102), no habrá paz mundial sin una paz entre las religiones. También para aportar en que el ser humano se reconozca como tal a través de su relación con el otro, quien puede que no comparta su misma religión, pero sí comparte el hecho de pertenecer a un mismo género: la humanidad, la que llegó a surgir, prolongarse y conservarse en el tiempo mediante un largo proceso evolutivo y la presencia de lo divino en lo humano.

El diálogo interreligioso puede presentarse desde formas tan simples a otras un tanto más complejas. Qué mayor simpleza del diálogo que la vida misma, trivial y cotidiana, donde compartimos nuestras penas y alegrías, nuestros problemas y preocupaciones, ya sea con nuestros familiares como con otras personas. Esto es el diálogo de la vida (véase Pontificio Consejo para el diálogo interreligioso de la Congregación para la Evangelización de los Pueblos, 1991).

\footnotetext{
${ }^{3}$ La inclusividad en el ámbito teológico de la aceptación de otras religiones tendría su "talón de Aquiles", ya que el cristianismo ha visto al resto de las religiones al interior de un "giro copernicano", donde las religiones distintas a la cristiana girarían en torno a Cristo. Cfr. Santamaría del Río (2011).
} 
Una segunda forma de vivenciar el diálogo interreligioso corresponde al diálogo de las obras, esto es, a la lucha por la justicia social y por la bien común llevada a cabo por personas que lo dan todo por el bienestar común de la sociedad.

Una tercera forma se encuentra en el diálogo de los intercambios religiosos por parte de representantes de las distintas tradiciones religiosas, reconociendo y valorando su propia herencia y sus valores.

Por último, el diálogo de la experiencia religiosa, el cual es vivenciado por cualquier persona que desee compartir a otros la manera en que vive su fe y lo que ésta provoca en ella, a partir de sus ritos.

El Cusano parece adherirse a dichas formas del diálogo en su obra La paz de la fe, puesto que quiso aportar desde su propia experiencia cotidiana, la cual se tornó en él un sentimiento de preocupación y dolor, tras ver cómo una de las ciudades que constantemente frecuentaba era arrasada por hombres que se llamaban a sí mismo religiosos, seguidores de una Deidad Ilamada Aláh. De ese modo, procura contribuir con su escrito a su época, para que las autoridades políticas y religiosas de los pueblos alcanzaran la paz.

Sin embargo, en Nicolás de Cusa el dialogo de los intercambios teológicos no se da del todo, porque para el Cusano, la única religión que tiene mayor peso es la cristiana, y por ende, alude al hecho de que son los otras religiones quienes deberían prestar mayor atención (Nicolás de Cusa, 1996, p.77) a los dogmas cristianos.

Lo mismo sucede con el dialogo de la experiencia religiosa, pues el Cusano solamente comparte vivencias rituales propias del cristianismo, tales como la eucaristía y el bautismo, sin mencionar ni mucho menos valorar, desde alguno de los personajes de la obra, las riquezas de otros cultos religiosos no cristianos.

No obstante, el Cusano tiende a ser inclusivista ${ }^{4}$ con respecto a la pluralidad religiosa, puesto que no niega que las religiones puedan por sus propios méritos brindar salvación. Afirma que "las diferencias de ritos no serán motivo de confusión, pues han sido establecidas y recibidas como signos sensibles de la verdad de la fe" (Nicolás de Cusa, 1996, p. 81).

Finalmente, el Cusano termina su obra afirmando que en realidad la diversidad religiosa, en el fondo, no implica diferencias en el culto a Dios que todos de alguna manera han presupuesto, sino en

\footnotetext{
${ }^{4}$ El inclusivismo es una postura teológica que concibe la revelación divina como un acontecimiento no exclusivamente para la religión cristiana. Es decir, la divinidad de alguna forma se ha manifestado en las otras religiones.
} 
aspectos rituales (Nicolás de Cusa, 1996, p. 89).

Con todo lo anteriormente señalado, se puede sostener entonces que la conferencia universal del Cusano, puede ser concebida como un precedente para el diálogo interreligioso. De hecho, eso es precisamente lo que buscaba - en su contexto - para lograr la concordia entre las religiones. Antes de ir a las conclusiones, quisiera, a modo de paréntesis, proponer algunas condiciones previas que podrían tomarse en cuanta al momento de llevar a cabo el diálogo interreligioso:

a) Interesarse por otras religiones es una preocupación por la salvación fuera de la iglesia, por una nueva manera de "hacer misión" y de la "evangelización".

b) Las religiones en su diversidad pueden perfectamente ser expresiones de lo divino, dispensadas en todas las culturas.

c) Según Jacques Dupuis (2001, p. 530), deberíamos reconocer por medio del diálogo interreligioso, la presencia viva del Espíritu en las diversas culturas, permitiendo que dicha actitud paradigmática forme parte de la labor y el rol decisivo de la Iglesia, convirtiéndose en una necesidad de poder satisfacer y cumplir. Considerando que "el espíritu sopla por donde quiere" (Jn.3,8).

d) Intentar definir los objetivos, el para qué y el qué se quiere conseguir. e) Una salvación universal por parte de Dios, independiente de las religiones.

\section{Conclusiones}

El principal objetivo que perseguía Nicolás de Cusa era conseguir la concordia o paz de la diversidad de ritos, es decir, de las distintas religiones, las que a pesar de poseer cada una distintas prácticas litúrgicas y rituales, apuntaban a la conformación de una única religión verdadera, con una articulación en distintas confesiones. Esto no significaba que la pluralidad religiosa tuviera que desaparecer, sino más bien que ella misma tenía en común el elemento divino como fundamento de la felicidad, del bien, de la vida eterna. A partir de aquellos aspectos comunes debía llegarse a consenso para que se diera la paz.

Por otra parte, en la Paz de la Fe, el Cusano ofrece una antropología teológica, donde la libertad juega un rol esencial, puesto que por medio de ella la paz podría ser posible. Sin embargo, la autonomía del ser humano se conecta con la fe, porque el hombre y la mujer son libres en cuanto a decidir si creen o no en un ser Todopoderoso. Libertad que ayudaría a la convivencia interreligiosa, pues como acertadamente afirma Solari: "la paz de la fe remite a la libertad, en la medida en que la paz es producto de un diálogo en el que 
participan las naciones y los cultos" (Solari, 2012). Y claro, si se quiere conseguir un consenso a través del diálogo debe ser necesariamente considerando y apelando a la libertad de los participantes, es decir, de las distintas religiones, sin obligar mediante la fuerza.
Por lo tanto, la propuesta de Cusa se convierte en un antecedente del paradigma teológico contemporáneo del diálogo interreligioso, aunque en su obra no se aprecie un diálogo bilateral sino unilateral, es decir, solamente desde el cristianismo, con otros credos y sus representantes.

\section{Referencias Bibliográficas}

Buber, M. (1949). ¿Qué es el hombre?. México, DF: Fondo de Cultura Económica.

Cortina Orts, A. (1999). Ciudadanos del mundo: hacia una teoría política de la ciudadanía. Madrid: Alianza, 1999.

D'Amico, C. (2012). La propuesta de tolerancia de Nicolás de Cusa. En R. Peretó Rivas (Ed.), Tolerancia: teoría y práctica en la edad media. Actas del coloquio de Mendoza (15-18 de junio de 2011) (Vol. 64, pp. 75-88). Porto: Fédération Internationale des Instituts d'Études Médiévales.

Dupuis, J. (2001). Hacia una teología cristiana del pluralismo religioso. Barcelona: Sal Terrae.

Küng, H. (1998) Proyecto de una ética mundial. Madrid: Trotta.

Nicolás de Cusa, N. (1996). La paz de la fe. Carta a Juan de Segovia. Cuadernos de Anuario filosófico. Serie universitaria, (26), 5-98. Recuperado de https://bit.ly/37CmQoM

Pontificio Consejo para el diálogo interreligioso de la Congregación para la Evangelización de los Pueblos (1991). Diálogo y anuncio. Recuperado de https://bit.ly/2sB8VQZ

Sampedro Nieto, F. (2013). Ecumenismo y Tercer Milenio. Nuevo manual de formación ecuménica. Bogotá: CELAM.

Santamaría del Río, L. (2011). La crítica de Gavin D’Costa a la teología pluralista de las religiones de John Hick. Anales de teología, 13(1), 61-118. 
Solari, E. (2012). De pace fi dei: de la libertad a la tolerancia. Teología y vida, 53(4), 439-473. http://doi.org/10.4067/S0049-34492012000300002.

\section{Para citar este artículo bajo Norma APA 6a ed.}

Rodríguez Medina, F. (2019). La paz de la fe de Nico-

lás de Cusa. Cuadernos de Teología - Universidad

Católica del Norte (En línea), 11, e3368,

https://doi.org/10.22199/issn.0719-8175-2019-0009

\section{DOI}

Copyright del articulo: @2019 Fabián Rodríguez

\section{(cc) BY}

Este es un artículo de acceso abierto, bajo licencia Creative Commons BY 4.0 